\title{
Refinement of the relationship between effective radii and ionization energies of alkali metal atoms
}

\author{
(C) Victor M. Yakovlev, ${ }^{1}{ }^{*}$ Ivan K. Garkushin, ${ }^{2}$ and Alexander V. Burchakov ${ }^{2+}$ \\ ${ }^{1}$ Samara State Transport University. Svobody St., 2B. Samara, 443066. Russia. \\ ${ }^{2}$ Samara State Technical University. Molodogvardeyskaya St., 244. \\ Samara, 443100.Russia.E-mail: turnik27@yandex.ru
}

\begin{abstract}
*Supervising author; ${ }^{+}$Corresponding author Keywords: effective atomic radius, orbital radius, specification of values, ionization energy, effective principal quantum number, alkali metals, analytical dependence.
\end{abstract}

\begin{abstract}
One of the key explanations for the peculiarities of the change in the first ionization energies (IE $E_{\mathrm{i} 1}$ ) of the elements of the periodic table is based on the postulation of an unambiguous relationship between $E_{\mathrm{i} 1}$ and atomic radii $\left(r_{\mathrm{at}}\right)$. Due to the certain conventionality of the rat parameters, they do not belong to the category of attributive atomic characteristics. Usually they are found either by implementing various kinds of theoretical or semi-empirical calculation schemes, or by using experimental data on $E_{\mathrm{i} 1}$ for the corresponding approximations. As follows from the literature data, the known values of rat, even in the case of "quasi-hydrogen-like" alkali metals (AM), relatively simple manyelectron systems - are characterized, as a rule, by a significant scatter. In addition, the canonical analytical formulas describing $r_{\text {at }}$ within the framework of a hydrogen-like model with two effective interaction parameters (according to Slater) do not ultimately lead to adequate results in this set of elements.

In this work, to correct the relationship $r_{\mathrm{at}}=f\left(E_{\mathrm{i} 1}\right)$ related to the properties of the aggregate of alkaline elements, the publication of the effective Slater radii $\left(r_{\text {eff }}\right)$ and Weber-Cromer orbital radii $\left(r_{\text {orb }}\right)$, and some results of later data are used. The effective principal quantum numbers $n *$ for each of the AM (except for $L i$, for which it is assumed that $n_{*}=n=2$ ) are estimated on the basis of the values of $E_{\mathrm{i} 1}$. A further step, by introducing $n_{*}$, made it possible to use the criterion for optimizing the value of the effective radius $r *$ and to correct the formula that determines its relationship with $E_{\mathrm{i} 1}$ in the form of a simple power function. At the same time, the radii $L i, N a$, and $\mathrm{Fr}$ have been refined towards some underestimation, compared with $r_{\text {orb. }}$. Arguments are presented in favor of the reliability of the proposed approach.

It is shown that the obtained estimates of $r *$ correlate better with the amplitudes of the solution of the wave equation covering all AMs than the known corresponding values of $r_{\text {orb }}$ and $r_{\text {eff. }}$

\section{References}

[1] E.V. Shpolsky. Atomic physics. The electron shell of the atom and the atomic nucleus. Ed. 2nd. MoscowLeningrad: Gostekhteorizdat. 1950. Vol.2. P.113-115. (russian)

[2] V.G. Tsirelson. Quantum chemistry. Molecules, molecular systems and solids. Moscow: BINOM. Knowledge laboratory. 2010. P.110-111. (russian)

[3] I.V. Saveliev. General physics course. Moscow: "Science". 1979. Vol.3. P.98-101. (russian)

[4] S.S. Batsanov. Experimental Foundations of Structural Chemistry. Moscow: Publishing house of standards. 1986. P.126. (russian)

[5] K.A. Waldron, E.M. Fehringer, E.A. Streeb et al. Screening percentages based on Slater effective nuclear charge as a versatile tool for teaching periodic trends. J. Chem. Educ. 2001. Vol.78. No.5. P.635-639.

[6] A.A. Radtsig, B.M. Smirnov. Parameters of atoms and atomic ions. Directory. Moscow: Energoatomizdat. 1986. P.74. (russian)

[7] E. Arnold, W. Borchers, H.T. Duong et al. Optical laser spectroscopy and hyberfine structure investigation of the $10^{2} \mathrm{~S}, 11^{2} \mathrm{~S}, 8^{2} \mathrm{D}$, and $9^{2} \mathrm{D}$ excited levels in francium. J. Phys. B. 1990. Vol.23. No.20. P.3511-3520.

[8] J.C. Slater. Atomic radii in crystals. J. Chem. Phys. 1964. Vol.41. No.10. P.3199-3204.

[9] J.T. Waber, D.T. Cromer. Orbital radii of atoms and ions. J. Chem.Phys. 1965. Vol.42. No.12. P.41164123.

[10] S.A. Shchukarev. Inorganic chemistry. Moscow: "Higher. school". 1970. Vol.I. P.64-67; Vol.II. 1974. P.3031. (russian)
\end{abstract}


[11] A.A. Godovikov. Periodic system of D.I. Mendeleev and the strength characteristics of the elements. Novosibirsk: "Science". 1981. 95p. (russian)

[12] S.S. Batsanov. Structural chemistry. Facts and dependencies. Moscow: Dialogue-MGU. 2000. P.180. (russian)

[13] J.K. Nagle. Atomic polarizability and electronegativity. J. Amer. Chem. Soc. 1990. Vol.112. No.12. P.4741-4747.

[14] V.F. Brattsev. Tables of Atomic Wave Functions, Ed. Veselova M.G. Leningrad: "Science". 1971. 456p. (russian)

[15] J. Emsley. Elements: trans. from English ed. Reutova O.A. Moscow: Mir. 1993. 256p. (russian)

[16] A.A. Potapov. Electronic structure of alkali metal atoms. Int. Scientific Research J. 2017. Iss.3. No.6(60). P.81-85. (russian)

[17] V.K. Ivanov. Electronic properties of metal clusters. SEJ. 1999. Vol.5. No.8. P.97-102. (russian)

[18] A.V. Konovalov, A.N. Ipatov. The role of polarization interaction in the photoionization of negative ions of alkali metals. ZhETF. 2017. Vol.152. Iss.3(9). P.465-474. (russian)

[19] A.M. Dyugaev, E.V. Lebedeva. Correspondence rules in atomic physics. Letters to ZhETF. 2016. Vol.103. Iss.1. P.62-66. (russian)

[20] V.M. Yakovlev. Relationship of effective charges of unperturbed atoms with the coordinates of chemical elements. Science and education for transport: Mater. XII int. scientific-practical conf. (Samara, November 6-7, 2019). Samara: SamSTU. 2019. Vol.2. P.187-191. (russian)

[21] T. Koga, K. Kanayama. Noninteger principal quantum numbers increase the efficiency of Slater-type basis sets: heavy atoms. Chem. Phys. Lett. 1997. Vol.26. No.1-2. P.123-129.

[22] N.L. Glinka. General chemistry. Ed. A.I. Ermakova. 30th ed. Moscow: Integral-Press. 2004. P.85-87. (russian)

[23] D.K. Ershov. Anti-shielding of the nuclear charge and the effects of relativism of electrons in the inner shells of atoms of heavy elements. Bulletin Universities. Physics. 2018. Vol.61. No.8. P.162-163. (russian)

[24] I.V. Martynov. Electronegativity as a function of the inverse radii of the atoms. RAS reports. 2001. Vol.378. No.5. P.647-649. (russian)

[25] I.F. Selyanin. Calculation of the energy of the ground state of two-electron atoms and ions. Journal. physical chemistry. 1977. Vol.51. No.12. P.3013-3016. (russian)

[26] A.M. Dyugaev, E.V. Lebedeva. New qualitative results in the theory of the atom. Letters to ZhETF. 2016. Vol.104. Iss.9. P.629-634. (russian) 